\title{
Discussion on the Cultivation of Problem Awareness Based on Social Science
}

\author{
Zeng Hui \\ Ningbo Dahongying University, Zhejiang Ningbo 315175, China
}

ABSTRACT. Problem consciousness is the starting point for the exploration and reflection of unknown areas, and it is the in-depth discovery and exploration of known fields and contradictions. On the basis of expounding the connotation of social science research and problem consciousness, this paper analyzes the necessity of problem consciousness for social science research, and believes that cultivating problem awareness in social science research should absorb the experience, innovate the knowledge structure, and create an academic atmosphere of benign development. To dilute the authority consciousness and dare to question three aspects.

KEYWORDS: Problem awareness, Social science, Approach

\section{Introduction}

In scientific research, problems are seen as the starting point and destination of research. If a discipline can produce a large number of problems, then it is full of vitality, and the lack of problems is a sign that the discipline lacks vitality and even declines. The conscious problem consciousness reflects the scholar's humanistic concern and responsibility to the society; the cultivation of problem consciousness requires the joint efforts of scholars and society.

\section{Problem awareness}

Marx said that the most difficult thing is not the answer, but the problem. Problem consciousness is a comprehensive reflection of various thinkings that question, explore, break through and verify contradictions in social practice or theory. Problem consciousness runs through social science research and is a necessary condition for social science research. Problem awareness includes four parts: problem finding, problem definition, and problem solving and result verification.

First, find the problem. It is the core content of problem consciousness. Finding the problem is the starting point of research. It refers to asking questions on the basis 
of careful observation and thinking in daily work, life and study, and always maintains a skeptical attitude. Second, define the problem. This is a process of turning an unknown problem into a knowing process, which is much more difficult than directly solving a problem that has already been defined. It requires researchers to launch visual, olfactory, sensory, tactile and other senses to perceive and experience, and to use image thinking, logical thinking, critical thinking and other ways of thinking to analyze and study the collected materials and information. Third,

Solve the problem. Researchers are required to use professional knowledge, argumentation tools and academic horizons to conduct surveys, forensics, analysis, and to find solutions to problems in multiple experiments. Fourth, the results are verified. This means that only research that can solve social problems can be regarded as a social research.

Problem consciousness is an indispensable basic requirement in scientific research. It is a suspicion and transcendence in existing things in society, and it is a truth-seeking and exploration of things in the future. However, the problem consciousness is not based on facts and science. It is not simply based on new ideas and unique behaviors. It is a study of social issues from different angles. Therefore, it is a social value difference. The problem consciousness has the characteristics of negation and criticality. Its philosophical basis is materialist dialectics. This kind of criticism is different from Kant's criticalism and different from the critical realism of Lovezoi et al. It is essentially a dialectical sublation. The new factors that arise from the development of things take its essence to its dross, thus promoting things in the right direction.

\section{Ways of cultivating problem awareness in social science research}

How can a person without sufficient knowledge reserves discover problems in the field? Even if problems are discovered, how can they solve these problems without the accumulation of knowledge and research experience? Persistence in problem orientation has always been a distinctive feature of Marxism. How to cultivate problem awareness is not only important, but also has very realistic meaning.

In social science research, the selection and determination of research topics has actually determined the direction and objectives of the research. The next step is to determine the specific content including the research content, research scope, and research objects. When determining the topic, the researcher is often influenced by the following factors: professional theoretical foundation, mastery of research methods, personal logical thinking ability and ability to mobilize social resources. That is to say, the knowledge structure of these aspects determines the researchers. The ability to find problems when selecting a topic. The level of a subject does not lie in whether the problem being studied is at the macro level or the micro level, but whether it can reveal the internal relationship of social phenomena, whether it can summarize the overall situation of social phenomena and the law of development at a relatively high level. Undoubtedly, the perfection of the researcher's knowledge 
ISSN 2616-5783 Vol. 1, Issue 1: 94-96, DOI: 10.25236/AJHSS.040013

structure determines the overall quality of the subject and the research results. The basis of problem consciousness lies in a solid reserve of professional knowledge and a broad academic vision. Reading and practicing are the most basic and important ways for social scientists to learn. Academic vision is the basic quality that social science researchers must possess. A broad academic vision helps to open up ideas and think about problems from different angles, thus providing a reference for solving problems. "Reading classics is especially important. There are several classic works in each subject. These classic works are the crystallization of human wisdom in all ages." Reading classics and reading masters is to absorb their wisdom and let them take less detours. This will allow you to grow faster. Therefore, social science researchers "standing on the shoulders of great people" and updating their knowledge structure in a timely manner can contribute to the cultivation of problem awareness and lay the foundation for improving academic innovation ability.

\section{Conclusion}

The emergence of any major academic achievement is a tireless and strong problem-consciousness that is manifested in the face of contradictory confusion in the development of things. Therefore, creating a good academic atmosphere, improving the teaching methods of teachers, and establishing a way of thinking that dares to question, has a certain role in promoting the cultivation of problem awareness.

\section{References}

[1] Tan Yipei. New Insights into the Study of the Nature of Archival Science (I) [J]. Lantai World, 2000 (6).

[2] Lao Kaisheng. Problem Consciousness, Academic Consciousness and Method Consciousness in Humanities and Social Sciences Research [J]. Journal of Beijing Normal University (Social Science Edition), 2009 (1).

[3] Qiu Liping. Social Research and Problem Awareness [J]. Journal of Jiangsu Administration Institute, 2010 (1). 